\title{
Hydrothermally Synthesized Strontium Peroxyapatite
}

\author{
Agnese Osite ${ }^{1, a *}$, Karlis Agris Gross ${ }^{2, b}$, Arturs Viksna ${ }^{1, c}$ \\ and Raimonds Poplausks ${ }^{3, d}$ \\ ${ }^{1}$ Department of Analytical Chemistry, University of Latvia, K. Valdemara Str. 48, Riga, LV-1013, \\ Latvia \\ ${ }^{2}$ Biomaterials Research Laboratory, Riga Technical University, Azenes Str. 14/24, Riga, \\ LV-1048, Latvia \\ ${ }^{3}$ Institute of Chemical Physics, University of Latvia, Kronvalda Blvd. 4, Riga, LV- 1010, Latvia \\ aagnese.osite@lu.Iv, 'Karlis-Agris.Gross@rtu.Iv, carturs.viksna@lu.Iv, ${ }^{d}$ raimonds.poplausks@lu.Iv
}

Keywords: strontium peroxyapatite, hydrogen peroxide, permanganatometric titration

\begin{abstract}
The current research focuses on peroxide ion incorporation in the structure of strontium hydroxyapatite (SrHAp) by exposure to $\mathrm{H}_{2} \mathrm{O}_{2}$ in a closed hydrothermal vessel under mild conditions at 130 to $170{ }^{\circ} \mathrm{C}$. Peroxide enriched strontium apatite (SrPerAp) was characterized for structure by $\mathrm{X}$-Ray diffraction, for peroxide content- by permanganometric titration and then viewed by SEM. This study continued from previous work that used $30 \% \mathrm{H}_{2} \mathrm{O}_{2}$ and showed a higher included peroxide content after processing with $50 \% \mathrm{H}_{2} \mathrm{O}_{2}$ at $130{ }^{\circ} \mathrm{C} 70 \%$ of the theoretical peroxide content in apatitic channels of strontium apatite. This is the highest peroxide content incorporated to date and employs a lower temperature than heating at $1300{ }^{\circ} \mathrm{C}$.
\end{abstract}

\section{Introduction}

Hydroxyapatite, (HAp), $\left[\mathrm{Ca}_{10}\left(\mathrm{PO}_{4}\right)_{6}(\mathrm{OH})_{2}\right]$ is a common biomaterial, that exhibits the characteristics for further improvement. This has direct implications for its use as a catalyst, LC column, lighting material, chemical sensor [1]. But more important is the wide range of clinical applications - both as coated implants in joint prostheses and as bone grafts for bone regeneration. Bone is a very complicated hierarchical material, fulfilling multiple functions (mechanical, biological and chemical), and has a unique ability for self-repair. The similarity with biological apatites provides almost excellent biocompability, although synthetic HAp can be improved to exhibit an antibacterial property [2].

Therefore, to minimize undesirable incidents of infection, it is necessary to improve the antibacterial properties of HAp. The apatite lattice is very tolerant of substitutions and HAp substitution with $\mathrm{Sr}$ is assumed favourable to modify apatite features in medicine [3, 4]. $\mathrm{Sr}$ as a trace element is present in the mineral phase of bone and as it enhances the bone strength, stimulates its' healing and formation, reduces bone resorption and lowers the risk of osteoporosis [5].

The other useful reagent for substitution is $\mathrm{H}_{2} \mathrm{O}_{2}$, also is found in the human body where it isgenerated by phagocytes to modulate the inflammatory processes. $\mathrm{H}_{2} \mathrm{O}_{2}$ is widely regarded as a harmful cytotoxic agent, but in low concentrations it has an important physiological role in the homeostatic maintenance of normal cell function [6].

Almost forty years ago peroxyapatites, containing oxygen in a -1 oxidation state in the lattice, were prepared at $1000{ }^{\circ} \mathrm{C}$ requiring heating for two days [7]. Oxygen enriched apatites were also obtained allowing $\beta$ tricalcium phosphate to react with boiling $\mathrm{H}_{2} \mathrm{O}_{2}$ for $15 \mathrm{~h}$ and then apatite was obtained by precipitation [8]. Later on, peroxyapatite was made by heat treatment at $1200{ }^{\circ} \mathrm{C}$ in dry oxygen gas followed by annealing was conducted at $800{ }^{\circ} \mathrm{C}$ for $2 \mathrm{~h}$ [9]. In a very recent study, the formation of strontium peroxy-hydroxyapatite solid solution was investigated at $900-1350{ }^{\circ} \mathrm{C}$ in oxygen, air and argon atmosphere [10]. Comparing the previously mentioned methods to the hydrothermal process treatment, used in the current study, the latter is less time-consuming and cheaper. But attention should be paid to the several parameters - such as providing high vapour 
pressure inside the steel pressure vessels and a constant stirring throughout the hydrothermal process is needed to obtain an evenly coloured powder.

Incorporation of $\mathrm{Sr}$ and peroxide in the apatite lattice would impart an antibacterial and anti inflammatory characteristic. Despite the intense research on hydroxyapatites in the last decades, very little research has been conducted on peroxyapatites and the most appropriate synthesis routes have still not been developed.

\section{Experimental}

Strontium hydroxyapatite (SrHAp) powder - used as the host for peroxide ions to create strontium peroxyapatite (SrPerAp) - was obtained by wet chemical method using two solutions. Solution A was prepared from $0.02 \mathrm{~mol}$ of $\mathrm{Ca}\left(\mathrm{NO}_{3}\right)_{2} \cdot 4 \mathrm{H}_{2} \mathrm{O}, 0.06 \mathrm{~mol}$ of $\mathrm{Sr}\left(\mathrm{NO}_{3}\right)_{2}$, and $0.4 \mathrm{~mol}$ of $\mathrm{NH}_{3}$ water solution, but solution B consisted of 0.03 mol of $\left(\mathrm{NH}_{4}\right)_{2} \mathrm{HPO}_{4}$ and $\left(\mathrm{NH}_{4}\right)_{2} \mathrm{CO}_{3}$ additive. Analytical grade chemicals were dissolved in deionised water and the two solutions mixed, the obtained suspension was stirred for 10 minutes at room temperature, washed, filtered and dried at $100{ }^{\circ} \mathrm{C}$ for $30 \mathrm{~min}$. According to Rey et al., SrHAp accommodates higher concentrations of oxygen, therefore 75\% substituted SrHAp was chosen for peroxide incorporation in the current research [8].

Synthesis of SrPerAp was performed in a closed system - hydrothermal steel pressure vessel (total volume $2.5 \cdot 10^{-5} \mathrm{~m}^{3}$ ) at temperatures of $130{ }^{\circ} \mathrm{C}$ to $170{ }^{\circ} \mathrm{C}$, contrary to Kazin who has used very high temperatures. $0.05 \mathrm{~g}$ of SrHAp powder and concentrated $\mathrm{H}_{2} \mathrm{O}_{2}$ solution were loaded in the hydrothermal steel pressure vessel and heated for 3 hours at adjusted temperature, then cooled until room temperature under cool air flow with cooling rate $1,5^{\circ}$ per min. At the first set of experiments $30 \%$ wt. $\mathrm{H}_{2} \mathrm{O}_{2}$ was used to confirm the reproducibility of previous results, but the second set of experiments used $50 \%$ wt. concentrated peroxide solution $\left(17.6 \mathrm{M} \mathrm{H}_{2} \mathrm{O}_{2}\right)$ to see if more peroxide could be included. Different volumes of $\mathrm{H}_{2} \mathrm{O}_{2}$ were further investigated as a means to incorporate more peroxide ions.

The classical permanganometric titration was used to determine the amount of $\mathrm{H}_{2} \mathrm{O}_{2}$ in peroxyapatite. Permanganometric titration involves two steps - the standardization of $\mathrm{KMnO}_{4}$ solution with oxalic acid standard and the titration of analyte. Peroxide titration is based on the reaction involving $\mathrm{MnO}_{4}^{-}$(purple) and $\mathrm{Mn}^{2+}$ as the redox couple in acidic medium. Powder of SrPerAp was dissolved in concentrated perchloric acid and then diluted with deionised water. The titration was performed using potassium permanganate solution $(0.001 \mathrm{M})$ until the stoichiometric point was reached as evidenced by the characteristic purple colour of permanganate ions.

The physico-chemical characterisation was followed by other complementary techniques. The obtained powder of SrPerAp was investigated by X-ray diffraction on a D8 Advance diffractometer (Bruker), recorded from $5^{\circ}$ till $60^{\circ}$ using $\mathrm{Cu} \mathrm{K \alpha}$ radiation $(\lambda=1.54180 \AA$ generated at $40 \mathrm{~mA}$ and $40 \mathrm{kV})$. A Scanning Electron Microscope (SEM) recorded views of the powder in a Hitachi S-4800 microscope operated at $7 \mathrm{kV}$.

\section{Results and Discussion}

Peroxide quantification. A classical redox titration quantified the peroxide content in strontium peroxyapatite samples, allowing the report of the peroxide content (expressed as a weight fraction against the theoretical $2.35 \%$ content, calculated from the chemical formula $\left.\mathrm{Sr}_{7.5} \mathrm{Ca}_{2.5}\left(\mathrm{PO}_{4}\right)_{6} \mathrm{O}_{2}\right)$ in a range of $\sim 0.36$ up to 0.70 . The degree of incorporation depended on the temperature of the hydrothermal process. These results confirmed the presence of peroxide ions in the composition of strontium apatite samples treated in $\mathrm{H}_{2} \mathrm{O}_{2}$ medium.

Due to poor peroxyapatite solubility in water, samples were dissolved in concentrated perchloric acid to liberate the peroxide ions for quantification by permanganometric titration. A small but noticeable gaseous release occurred during sample dissolution in perchloric acid. It was assumed that the released gas is molecular oxygen. That could be explained not only by the presence of such oxygenated species as $\mathrm{H}_{2} \mathrm{O}_{2}$ or peroxide ions $\mathrm{O}_{2}{ }^{2-}$, but also by superoxide ions $\mathrm{O}_{2}{ }^{-}$as it is reported 
by other researchers [11]. Both $\mathrm{O}_{2}{ }^{2-}$ and $\mathrm{O}_{2}{ }^{-}$show different hydrolysis reactions in acidic medium (Eq. 1, 2).

$$
\begin{aligned}
& \mathrm{O}_{2}^{2-}+2 \mathrm{H}_{3} \mathrm{O}^{+} \rightarrow \mathrm{H}_{2} \mathrm{O}_{2}+2 \mathrm{H}_{2} \mathrm{O} \\
& 2 \mathrm{O}_{2}^{-}+2 \mathrm{H}_{3} \mathrm{O}^{+} \rightarrow \mathrm{H}_{2} \mathrm{O}_{2}+2 \mathrm{H}_{2} \mathrm{O}+\mathrm{O}_{2}
\end{aligned}
$$

As the permanganometric titration quantifies only peroxide molecules and peroxide ions $\mathrm{O}_{2}{ }^{2-}$, this redox titration method is not suitable for quantification of superoxide. The $\mathrm{O}_{2}{ }^{-}$hydrolysis reaction additionally enriches the content of peroxide determined in strontium peroxyapatite, thus not only peroxide incorporates in the apatitic lattice channels but $\mathrm{H}_{2} \mathrm{O}_{2}$ molecules could possibly be linked to the apatite surface like water molecules.

At the first step of the current investigation, a $30 \% \mathrm{wt}$. peroxide solution was used for peroxide incorporation into $\mathrm{OH}$ channels of strontium hydroxyl-apatite. Previous work showed successful incorporation of peroxide by hydrothermal processing at $150{ }^{\circ} \mathrm{C}$ [12]. Results of the previous and the current research were comparable - a difference of 0.02 in the peroxide content lies within the experiment error. The use of $50 \%$ wt. $\mathrm{H}_{2} \mathrm{O}_{2}$, instead of $30 \% \mathrm{wt}$, increased the incorporated peroxide content by $35 \%$, Fig 1 .

Permanganometric titration results illustrate an optimum powder $/ \mathrm{H}_{2} \mathrm{O}_{2}$ ratio for inclusion of peroxide ions in strontium apatite. A greater powder loading provided a lower incorporation of peroxide [12], Fig. 2. The resulting peroxide content increased and reached a maximum with a $3.5 \mathrm{~mL} \mathrm{H}_{2} \mathrm{O}_{2}$ volume, but greater $\mathrm{H}_{2} \mathrm{O}_{2}$ volumes led to a decrease in peroxide content, Fig. 2.

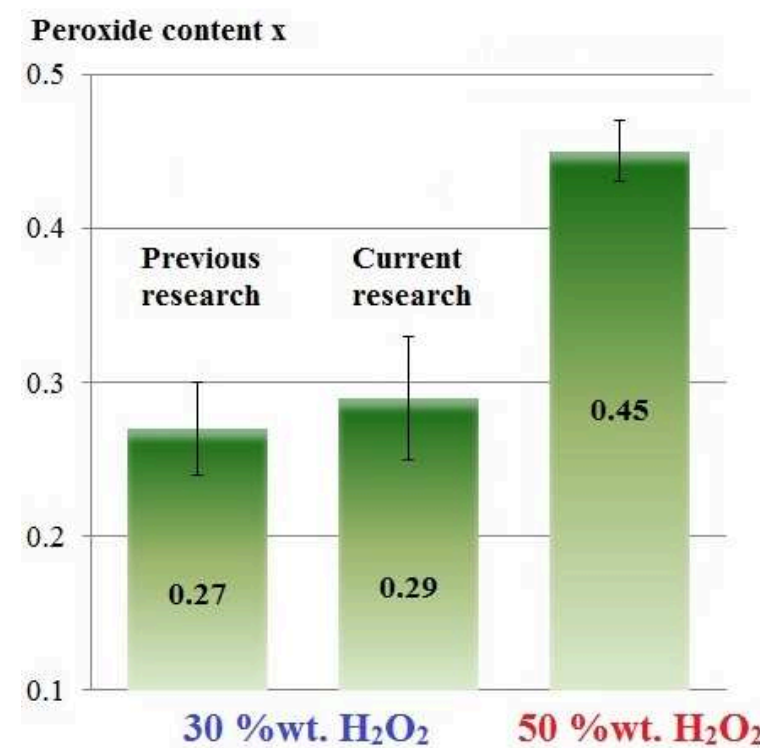

Fig. 1. Peroxide content in SrPerAp made at 150 ${ }^{\circ} \mathrm{C}$ depends on $\mathrm{H}_{2} \mathrm{O}_{2}$ concentration

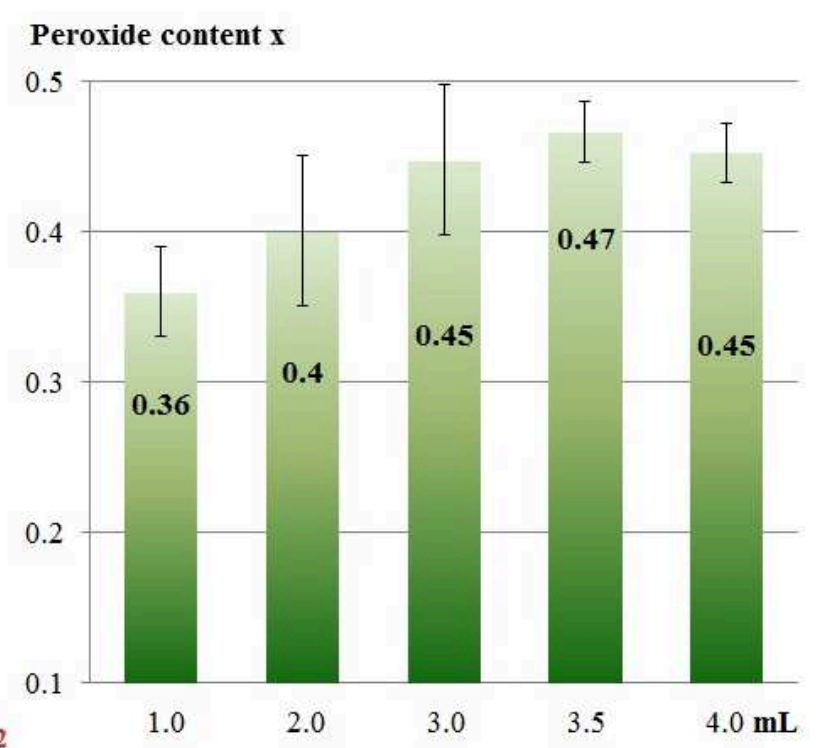

Fig. 2. Peroxide content in SrPerAp (obtained at $150{ }^{\circ} \mathrm{C}$ ) as a function of $\mathrm{H}_{2} \mathrm{O}_{2}$ volume

The titrimetric results of peroxide showed greater concentrations at lower processing temperatures; only $36 \%$ of the theoretical possible peroxide was included at $170{ }^{\circ} \mathrm{C}$, but twice as much was incorporated at $130{ }^{\circ} \mathrm{C}$, Fig. 3. Processing at $130{ }^{\circ} \mathrm{C}$ has included just as much as Kazin [10] was able to include at temperatures in excess of $1200^{\circ} \mathrm{C}$. Other processing methods have only included up to $59 \%$ peroxide.

X-Ray Difraction analysis. Starting SrHAp powders showed an amorphous structure in XRD patterns. The XRD pattern (compared with the PDF-2 2012, ICDD) of all powders synthesized at a remarkably lower temperature $\left(150{ }^{\circ} \mathrm{C}\right.$ compared to $\left.1200{ }^{\circ} \mathrm{C}[10]\right)$ under vapour pressure displayed diffraction peaks characteristic of well-crystallized peroxyapatite, Fig. 4. This independently confirms that the previously developed method of peroxyapatite synthesis is reproducible at a lower temperature [12]. 


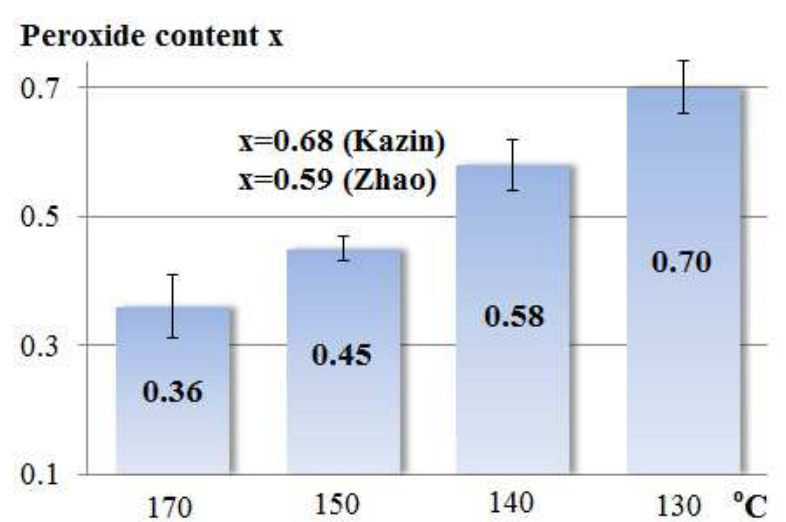

Fig. 3. Peroxide content in SrPerAp as a function of temperature of the hydrothermal process with $50 \% \mathrm{H}_{2} \mathrm{O}_{2}$

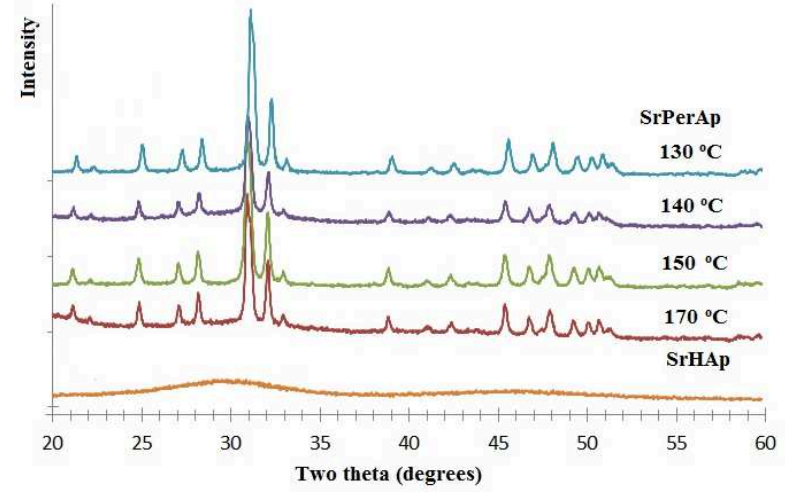

Fig. 4. XRD patterns of SrHAp and SrPerAp

SEM analysis. SEM micrographs of SrPerAp synthesized at $150{ }^{\circ} \mathrm{C}$ showed elongated particles formed by joining of individual spherical particles during peroxide inclusion. The average crystal size is $160 \mathrm{~nm}$ long and $70 \mathrm{~nm}$ wide. The structure of SrHAp before peroxide treatment represented individual spherical particles.

\section{Summary}

The use of $50 \%$ wt. $\mathrm{H}_{2} \mathrm{O}_{2}$ increases the incorporated peroxide content by at least $35 \%$. The amount of incorporated peroxide ions depends on the amount of $\mathrm{H}_{2} \mathrm{O}_{2}$ and the treatment temperature. The newly developed synthesis method for making peroxyapatite at lower temperature (even at $130{ }^{\circ} \mathrm{C}$ ) is suitable, less time consuming and simpler for obtaining well crystallized strontium peroxyapatite, confirmed by X-ray diffraction. In future investigations, more concentrated hydrogen peroxide $60 \%$ wt. will be explored to see if more peroxide can be included in the lattice.

\section{Acknowledgement}

Support from the ESF project 2013/0028/1DP/1.1.1.2.0/13/APIA/VIAA/054 is gratefully acknowledged. This project falls under the activities of the Refined Step project, PIRSES-GA-2013612691 described in www.createyourbiomaterial.eu

\section{References}

[1] A. Bigi, E. Boanini, C. Capucini, M. Gazzano, Inorganica Chimica Acta. 360 (2007) 1009-1016.

[2] L. Yingguang, Y. Zhuoru, C. Jiang, W. Lianshi, J. Wuhan. Uni. Technol. Mater. (2008) 475479.

[3] S.P. Nielsen, The biological role of strontium. Bone. 35 (2004) 583-588.

[4] J. Terra, E.R. Dourado, J.G. Eon, D.E. Elis, G. Gonzalez, A.M. Rossi, Phys. Chem. Chem. Phys. (2009) DOI: 10.1039/b802841a.

[5] M.D. O’Donnell, Y. Fredholm, A. de Roufgnac, R.G. Hill, Acta Biometerialia. 4 (2008) 14551464.

[6] B. Halliwell, M.V. Clement, L.H. Long, FEBS Letters. 486 (2000) 10-13.

[7] J.C. Trombe, G. Montel, J. Inorg. Nucl. Chem. 40 (1978) 23-26.

[8] C. Rey, J.C. Trombe, G. Montel, J. Inorg. Nucl. Chem. 40 (1978) 27-30.

[9] H. Zhao, X. Li, J. Wang, S. Qu, J. Weng, X. Zhang, J. Biomed. Mater. Res. 52 (2000) 157-163.

[10] P.E. Kazin, M.A. Zykin, R.E. Dinnebier, O.V. MagDysyuk, Y.D. Tretyakov, M. Jansen, Z. Allg. Chem. 638 (2012) 909-919.

[11] N. Vandecandelaere, F. Bosc, C. Rey, C. Drouet, Powder Technol. 255 (2014) 3-9.

[12] K.A. Gross, A. Jersova, A. Viksna, Key Eng. Mater. 631 (2014) 88-92. 